\title{
CONHECIMENTO LINGUÍSTICO DO PROFESSOR DE PORTUGUÊS EM PRÁTICAS DE REGULAÇÃO E DE AVALIAÇÃO: DO ENUNCIADO INSTRUCIONAL AO ITEM DE RESPOSTA ${ }^{1}$
}

RESUMO: No processo de ensino e de aprendizagem, o enunciado instrucional funciona como uma ferramenta mediadora e orientadora da atividade de ensinar. Por esta razão, as regras de codificação dos enunciados instrucionais devem ser bem conhecidas quer por parte dos professores, quer por parte dos alunos. Sabendo que é uma das formas de os professores recolherem informação sobre a promoção da aprendizagem da escrita e o desempenho nos percursos dessas aprendizagens feitas pelos alunos, este trabalho tem por foco os enunciados instrucionais e a sua formulação para atividades de resposta extensa. Analisam-se exemplos de enunciados e reflete-se sobre a sua formulação na relação com o conhecimento linguístico que o professor deve possuir.

PALAVRAS-CHAVE: conhecimento linguístico do professor, ensino e aprendizagem da escrita, avaliação, enunciados instrucionais

ABSTRACT: In the process of teaching and learning, the instructional statement functions as a mediating and guiding tool for the teaching activity. For this reason, the coding rules for instructional statements should be clear to both teachers and students. Understanding that this is one of the means in which teachers can gather information - on the promotion of writing and

\footnotetext{
${ }^{1}$ Este trabalho faz parte do projeto de pós-doutoramento financiado pela Fundação para a Ciência e a Tecnologia, com a Referência de Bolsa SFRH/BPD/111294/2015, desenvolvido no Centro de Linguística da Universidade do Porto, que conta com o apoio financeiro da Fundação para a Ciência e a Tecnologia, através do financiamento atribuído ao respetivo Centro ao abrigo do Fundo de Reestruturação de Unidades 2016 Ref". UID/LIN/0022/2016.
} 
on the performance in the course of those learnings made by students -, this work focuses on instructional statements and their formulation for extensive answer activities. Examples of instructional statements are analyzed, and their formulation is reflected upon in relation to the linguistic knowledge that the teacher must possess.

KEYWORDS: teacher's linguistic knowledge, teaching and learning of writing, assessment, instructional statements

\section{1 - Apresentação da questão}

$\mathrm{O}$ ato de "avaliar", segundo Neves \& Ferreira, convoca uma quantidade de questões sobre a sua finalidade como "Atingir objetivos? Medir? Verificar? Reportar? Descrever? Compreender? Formular juízos? Sustentar decisões? Fazer exames? Atribuir classificações? Melhorar? Registar? Progredir? Seriar? Selecionar? Certificar? Aferir? Regular? Acompanhar? Classificar?" (2015: 23), tornando a sua definição complexa. A avaliação constitui, no processo de ensino e de aprendizagem, um dos grandes desafios deste processo quer na perspetiva dos professores, quer na perspetiva dos alunos. Na mediação da relação entre estes três polos distintos - avaliação, alunos e professores -, encontra-se o conhecimento: o que é ensinado, o que é aprendido e o que é avaliado. Para se efetivar este processo, são elaborados instrumentos constituídos por um conjunto de itens que enunciam, de forma clara, tarefas a realizar pelos respondentes (Neves \& Ferreira 2015: 91). O item instrucional ou o enunciado instrucional que solicita a/uma resposta assume uma função mediadora na atividade de ensino e de aprendizagem por representar, assim, uma atividade de linguagem (Riestra 2010).

O texto instrucional constitui-se como uma das práticas escolares mais recorrentes e menos analisadas criticamente (Duarte et al. 2016). Os enunciados instrucionais estabelecem um eixo importante no processo ensino-aprendizagem da língua e, claro, de qualquer disciplina, contrastando esta situação com a pouca importância conferida a esta dimensão do discurso pedagógico. A análise da formulação de enunciados instrucionais, nas suas diferentes modalidades, permite recolher algumas considerações relativas às conceções dos docentes sobre a avaliação subjacente ao processo de ensino e de aprendizagem da escrita, nomeadamente, dos itens de resposta extensa (Neves \& Ferreira 2015), e sobre a orientação dada aos processos comunicativos em aula de itens/enunciados de avaliação ou itens/enunciados das atividades presentes em manuais.

\section{2 - Enunciado instrucional e a prática de regulação e de avaliação}

Como já se referiu, o conceito de avaliação é de difícil definição; no entanto, independentemente das perspetivas que possam estar subjacentes 
a este conceito, é consensual que na sua origem se considere que "avaliar pressupõe a existência de recolha de informação" (Neves \& Ferreira 2015: 23), e especificamente no processo de ensino-aprendizagem. Para tal, criam-se tarefas, atividades que permitem ao professor recolher informação sobre o nível de desempenho dos seus discentes nos diferentes conteúdos e, ao mesmo tempo, fornecem orientações ao professor sobre o seu desempenho e ajudam a (re) definir e (re)orientar a sua prática. Os enunciados instrucionais, que podem ser itens de seleção - escolha múltipla, associação, ordenação, verdadeiro/falso, completamento - ou itens de construção - completamento, resposta curta, resposta restrita, resposta extensa (Neves \& Ferreira 2015: 91-92) -, efetivam a mediação entre os polos da relação construída: pela regulação/avaliação, pelos alunos e pelos professores.

Uma vez que os enunciados instrucionais possuem este valor no processo de ensino-aprendizagem, devem ser objeto de reflexão: até que ponto os professores relacionam a formulação dos enunciados instrucionais com a avaliação e até que ponto esses enunciados vão ao encontro das necessidades dos alunos na concretização das tarefas de escrita. Os itens instrucionais - presentes nos testes de avaliação, nos materiais trabalhados em aula ou nos manuais - constituem o nível metadiscursivo que mais implicações tem no contexto de sala de aula (Vieira de Castro 1995, 1998; Tormenta 2003). Tendo em conta o trabalho didático subjacente às atividades de escrita, no que se refere a confrontar os alunos com situações de produção neste domínio, pressupõe-se uma complexidade progressiva do processo de elaboração de textos. González, num trabalho que desenvolveu sobre a implicação dos enunciados instrucionais nas atividades de produção textual propostas em sala de aula, refere que os "diferentes modos de levar a cabo as tarefas de uma actividade intelectual devem ser accionados intencionalmente pelo sujeito mais competente e devem incidir numa actuação reflectiva por parte dos sujeitos em fase de desenvolvimento." (2005: 184), potenciando a progressão na produção de textos. Os enunciados instrucionais fazem parte deste processo e são apenas um dos aspetos a ter em conta na criação de condições necessárias no momento de proporcionar atividades de escrita.

\section{3 - Enunciado instrucional: uma questão de comunicação}

Neste trabalho, assume-se o foco nos enunciados instrucionais e na sua formulação para resposta extensa, que constituem uma das formas de os professores recolherem informação sobre a promoção da aprendizagem da escrita e o desempenho nos percursos dessas aprendizagens feitas pelos seus alunos. A função mediadora destas instruções (Riestra 2010) representa (um)a forma de comunicação, um ato de interação, entre o professor e o aluno, de onde resultará a regulação/avaliação. Os enunciados são aqui assumidos 
como atos comunicativos, atos de interação, porque vão desencadear uma situação de comunicação, através da linguagem, entre professor e alunos. De acordo com os princípios da interação, esta troca comunicativa exige que se exerçam influências recíprocas entre os dois participantes: codificador/ produtor e descodificador/recetor (Kerbrat-Orecchioni 1990: 17). Esta perspetiva permite-nos afirmar que, a partir de uma abordagem históricocultural, a prática reguladora/avaliativa dos conhecimentos, no processo de ensino e de aprendizagem, assenta no aspeto dialógico e social da linguagem (Vygostsky 1998; Bakthin 2003). O enunciado instrucional criado, uma atividade de linguagem (Bronckart 2003), funciona, neste processo, como uma ferramenta de intervenção da atividade de ensinar, fazendo com que o conhecimento linguístico do professor de português, necessário à produção desses enunciados instrucionais, tenha de se enquadrar numa base de interação adequada (van Dijk 2016) com o seu contexto natural e social, para se tornar eficaz. As marcas de interatividade possuem relevância no ato comunicativo uma vez que orientam o ato entre os interlocutores. Segundo Marcuschi, as marcas de interatividade atuam como operadores de orientação cognitiva, sugerindo perspetivas de interpretação preferencial por parte de quem escreve. Mais do que simples marcas estilísticas, são atos de fala (formas de ação) que fazem propostas, negociações, contratos e definem posicionamentos para uma relação intersubjetiva ou interação comunicativa mais eficaz (2001: 13). Concretizando esta relação intersubjetiva na situação de codificação e descodificação de uma instrução, existe um locutor - papel desempenhado pelos professores que "dizem/ escrevem" alguma coisa a/para alguém que é, no processo de ensino e de aprendizagem, configurado pelos alunos. O processamento textual, quer em termos de produção quer em termos de compreensão, vai depender sempre de uma interação entre produtor e interpretador (Koch 2002). No contexto de uso do enunciado instrucional, o que é produzido assume uma determinada forma e é configurado por escolhas linguísticas, com uma determinada intencionalidade: aperfeiçoar/verificar/testar/antecipar os conhecimentos que os alunos possuem ou devem possuir, num determinado contexto histórico-social - escola -, e a interlocução está revestida de determinadas condições - indicações programáticas - a que o aluno está/estará sujeito. Resumindo, a compreensão dos enunciados instrucionais está dependente de uma competência linguística e textual específica: quer seja da parte do locutor (que constrói o enunciado) - professor ou autor de manuais -, quer seja daqueles que têm de descodificar o enunciado: os interlocutores - os alunos.

Relativamente a este assunto do estudo dos instrumentos avaliativos/ regulativos, Amor (1999) desenvolveu uma extensa e profunda análise 
crítica e posicionamento próprio sobre a necessidade de uma competência linguística e textual específica na construção dos testes/provas de avaliação. Para esta autora:

Os instrumentos avaliativos postulam uma competência linguística e textual específica, por parte de professores e alunos, destinadores e destinatários de um tipo de textos altamente padronizado - os testes/provas de avaliação, cujas regras de codificação ambos devem dominar, no exercício dos seus distintos papéis, ainda que tais regras não cheguem a constituir, em si, objeto de estudo; a linguagem da avaliação constitui um subsistema da linguagem instrucional que também se pressupõe, de parte a parte, como adquirido, o que nem sempre se verifica.

Amor (1999: 27)

Tendo como princípio orientador as aprendizagens dos alunos, no processo de ensino-aprendizagem, fica claro que deve existir uma competência linguística partilhada entre o locutor e o interlocutor no que aos enunciados instrucionais diz respeito. No momento de regular as aprendizagens, a forma como se codifica e a sua consequente descodificação têm implicações na verificação das aprendizagens realizadas. A situação comunicativa representada pelo enunciado instrucional deve constituir-se por dados marcadamente objetivos, dados esses que devem ser (re)conhecidos pelos alunos, por serem resultantes de representações interiorizadas/apre(e)ndidas ao longo do processo de ensino e de aprendizagem e que os alunos mobilizam no decorrer do processo interativo, ou seja, no momento em que descodificam o enunciado instrucional para produzir o texto solicitado.

\section{4 - O enunciado instrucional e o conhecimento linguístico do professor de português}

Como qualquer profissão, o ensino requer que o seu profissional possua e construa um domínio relativo a um conjunto de conhecimentos específicos que a identifica, que a reconhece e que a destaca na sociedade pelo facto de possuir um conhecimento próprio, constituindo um grupo com características específicas. No caso do ensino, esse domínio de saberes, uma vez adquirido, passa por um processo de sistematização e, consequentemente, é transmitido a outros (Shulman 2004).

Roldão (2007) explicita razões para a necessidade de se observar de forma pormenorizada o conhecimento do professor:

A atividade de ensinar - como sucedeu com outras atividades profissionais - praticou-se muito antes de sobre ela se produzir conhecimento sistematizado. Estas profissões transportam por isso uma inevitável "praticidade" que, a não ser questionada/teorizada, jamais transformaria a atividade em ação profissional e mantê-la-ia prisioneira de rotinas não questionadas e 
incapazes de responder à realidade. Todavia, a progressiva teorização da acção, neste como noutros domínios, foi gerando, por sua vez, novos corpos de conhecimento, que passam a alimentar - e a transformar - a forma de agir dos profissionais em causa.

(Roldão 2007: 97)

A evolução da sociedade foi criando exigências no que se refere à função de ensinar. Entre as transformações operadas na sociedade e a mudança daí originada na forma de encarar o processo de ensino e de aprendizagem, ocorre um processo inter-relacional que dá origem a novo(s) questionamento(s). O resultado é um desenvolvimento do conhecimento que seja capaz de dar respostas à realidade de cada momento presente na evolução. Surge a necessidade de relacionar o ato de ensinar com todo um conjunto de dimensões que fazem parte de cada momento da história e que se podem representar por questões como: O que ensinar?; Como ensinar?; A quem ensinar?; Com que finalidade ensinar?; Que recursos estão disponíveis para ensinar?; entre muitas outras. Partindo desta perspetiva, o conhecimento que o professor deve possuir deve estar relacionado com as questões anteriormente colocadas, constituindo o que Shulman considera como o conhecimento do conteúdo (Shulman 1987). Este não é o único conhecimento que o professor de língua materna deve deter; é, igualmente, necessário um conhecimento didático explícito, designado como o conhecimento pedagógico do conteúdo (combinação entre o conteúdo e pedagogia) ${ }^{2}$.

$\mathrm{O}$ autor ressalva que, no que se refere aos professores, o PCK (Conhecimento Pedagógico do Conteúdo) é o conhecimento exclusivo da classe profissional docente por constituir a capacidade de transformar, ou seja, a capacidade de transformação do conteúdo que vai permitir distinguir um professor de uma disciplina de um especialista dessa mesma disciplina. Esta diferença reside no facto de que a conceção de PCK, para Shulman, representa não só os conhecimentos das representações do conteúdo específico a ensinar, como também das estratégias instrucionais, por um lado, e da identificação e compreensão das dificuldades e fragilidades da aprendizagem dos alunos, por outro, bem como das conceções dos mesmos por um determinado conteúdo programático. Na esteira de Shulman (1987), Grossman (1990) adapta este modelo e considera que o PCK é o

\footnotetext{
${ }^{2}$ Para além do conhecimento do conteúdo e do conhecimento pedagógico do conteúdo, aquele que nos vai interessar neste trabalho, Shulman (1987) destaca outras categorias necessárias à constituição do conhecimento do docente para ensinar: o conhecimento curricular (conhecimento relacionado com os programas e os meios disponíveis para o colocar em prática), o conhecimento pedagógico geral (aquele que se refere aos princípios e estratégias úteis para ensinar o conteúdo), o conhecimento dos alunos (as suas características e as suas capacidades), o conhecimento dos contextos educativos (o contexto de trabalho e o contexto social, cultural e económico envolvente da escola) e o conhecimento dos fins educacionais e de seus fundamentos filosóficos e históricos.
} 
conhecimento central constituído pelo conteúdo e pela forma como se ensina o conteúdo: conhecimento das capacidades de compreensão dos alunos, conhecimento do currículo e conhecimento das estratégias instrucionais. É através do cruzamento entre o conhecimento especializado do conteúdo e do conhecimento pedagógico desse conteúdo que o professor produz os enunciados instrucionais.

O professor de português deve possuir um conhecimento especializado do conteúdo que ensina, o que lhe permite tornar esse conteúdo mais compreensível ao seu aluno. Este conhecimento especializado do conteúdo é, portanto, necessário apenas ao professor, que pretende que o outro (aluno) entenda verdadeiramente o que faz, como faz e por que razão o faz e não o execute meramente como um conjunto de procedimentos. Trata-se do conhecimento da língua especificamente relacionado com o ensino e não é utilizado noutros contextos que não o de ensino; é um conhecimento exclusivo do professor. A promoção do desenvolvimento e aperfeiçoamento em língua materna dos alunos, e assumindo o professor de português um papel de destaque na e para a aprendizagem dos mesmos, apenas poderá ser possível se o professor for, ele mesmo, detentor de um conhecimento sobre o assunto que lhe permita, posteriormente, preparar e implementar tarefas desafiadoras e possibilitadoras dessa promoção. No caso do professor de português, o conhecimento/saber do conteúdo - língua - é apenas uma das dimensões do conhecimento do professor de português, aquela que nos vai interessar no presente trabalho.

A tarefa de ensinar a ler e a produzir textos é uma tarefa complexa, que exige ao professor investimento e qualificação. Assim, ensinar a ler e escrever, levando o aluno a lidar com a escrita em diferentes contextos, nomeadamente os contextos escolares, requer o já referido conhecimento linguístico e conhecimento pedagógico. O professor de português, no que ao domínio da escrita - item de resposta extensa - diz respeito, deve prever um resultado: quando solicita um determinado produto textual, deve elaborar o enunciado instrucional de acordo com o resultado que procura que os seus alunos sejam capazes de produzir. Deve estar consciente da relação intrínseca entre esse produto final e o enunciado instrucional que o requer. O professor deve ter conhecimento das regras de codificação das instruções e da importância que a instrução tem no aluno no desencadeamento do processo que leva à realização da atividade de escrita. Também o aluno deve estar familiarizado com as regras e as condições de (des)codificação das instruções (Amor 1999). O enunciado instrucional desempenha um papel fundamental na planificação e orientação do texto a produzir, uma vez que esse enunciado deve orientar a produção escrita de determinado texto e especificar o contexto em que se insere (Atorresi 2005). 
Os enunciados instrucionais possuem informações que são determinantes no momento da realização/concretização das tarefas solicitadas. A clareza da construção do enunciado e a pertinência das informações fornecidas contribuem para que o aluno, ao descodificar o que lê, tenha a possibilidade, segundo Dolz et al. (2011), de criar uma representação do modelo do produto final que tem de produzir. Ao conseguir construir uma representação desse quadro comunicativo, será mais fácil para o aluno assumir uma atitude enunciativa e com sentido na realização da tarefa, conseguindo dar resposta à questão "o que quero representar escrevendo este texto?". Para representar mentalmente, ou por esquema, esse quadro comunicativo, o enunciado deve dar conta de informações de caráter pragmático-discursivo-textual que estão relacionadas com a função comunicativa da escrita. Neste processo, tornam-se importantes indicações como a dos papéis sociais (enunciador e coenunciador), da intencionalidade do ato de escrita (objetivo comunicativo) e do lugar social onde o texto produzido pode/poderá circular (instituição e lugar de circulação do texto). Estas informações tornam-se relevantes para uma eficaz planificação e consequente produção textual na obtenção de um objeto comunicativo coerente com o enunciado. Uma vez que estas informações são necessárias para a construção da posição enunciativa, elas devem fazer parte do enunciado instrucional para, assim, conduzirem o aluno na realização da(s) tarefa(s). No entanto, Amor chama a atenção para o facto de o nível microestrutural dos instrumentos avaliativos ser o nível onde os mecanismos da linguagem e da textualidade são mais visíveis e no qual, tradicionalmente, o construtor de instrumentos de avaliação investe mais, embora muitas vezes sem a disciplina e o suporte técnico necessários. (1999: 34).

\section{1 - Níveis de conhecimento linguístico requeridos na formulação dos enunciados instrucionais para a escrita}

Tendo em vista as aprendizagens dos alunos e a regulação e a avaliação que a partir delas se faz, como anteriormente se referiu, o conhecimento específico que o professor de português deverá possuir, relativamente às regras subjacentes à formulação dos enunciados instrucionais para o item de resposta extensa, pressupõe uma competência linguística de diferentes níveis: lexical, morfossintática, textual, discursivo-pragmática. Segundo Amor (1999), este conhecimento deverá existir por parte de quem formula as instruções e, simultaneamente, por parte dos alunos. Estes últimos devem estar familiarizados com este tipo de enunciado instrucional, contribuindo, assim, para a produção do discurso escrito. Os alunos só adquirem e desenvolvem este conhecimento se ele for transmitido e trabalhado em sala de aula. 
Considerem-se, como exemplos, os seguintes enunciados instrucionais que nos servirão de base a este ponto do trabalho:

\section{Exemplo 1}

Escreve um texto no qual apresentes a tua opinião sobre o abandono de animais. Escreve os teus argumentos. ${ }^{3}$

\section{Exemplo 2}

Escreve uma carta com 100 a 150 palavras dirigida a um amigo para o aconselhares relativamente à forma como deve comemorar uma época especial do ano. ${ }^{4}$

\section{Exemplo 3}
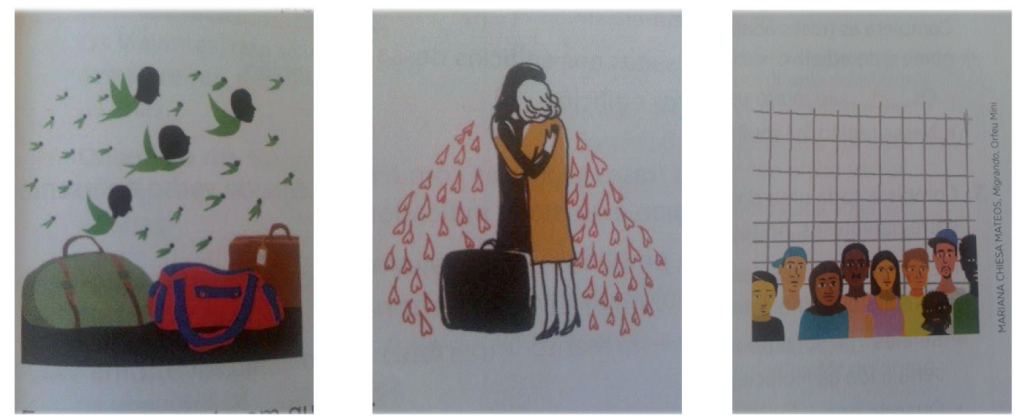

Escreve um texto em que:

Numa primeira parte, descrevas pormenorizadamente as imagens apresentadas;

Numa segunda parte, estabeleças uma relação entre elas, justificando a tua opção.

O teu texto deve ter um mínimo de 140 e um máximo de 200 palavras. ${ }^{5}$

\subsection{1 - Nível lexical}

O nível lexical é aquele que está mais diretamente relacionado com a área específica da(s) disciplina(s). No caso do português, nos itens de resposta extensa, tem-se como base de referência o léxico considerado normativo para o domínio da escrita. Na construção dos enunciados instrucionais, torna-se relevante recorrer a vocabulário que designe especificamente as operações

\footnotetext{
${ }^{3}$ Exemplo retirado de um teste diagnóstico de 9. ${ }^{\circ}$ ano.

${ }^{4}$ Exemplo retirado de um teste de $9 .^{\circ}$ ano.

${ }^{5}$ Exemplo retirado do manual de $9 .^{\circ}$ ano $P 9$, da Texto Editora.
} 
cognitivas subjacentes às tarefas propostas aos alunos, como por exemplo: escrever, descrever, caracterizar, argumentar, expor, relacionar, redigir, desenvolver, produzir, entre outros. A utilização precisa destes verbos de comando (Bloom 1956/1996), em cada enunciado instrucional, de acordo com os objetivos da tarefa, contribui para tornar a solicitação expressa, por esse mesmo enunciado, mais objetiva e apropriada, levando os alunos a uma melhor compreensão e, consequentemente, eficaz concretização, situação que não parece ter sido bem conseguida no exemplo 3. Este enunciado instrucional convoca para a mesma tarefa um conjunto de operações do domínio cognitivo que vão do ato de descrever ao relacionar e argumentar, sem estar enquadradas por uma tipologia textual, o que cria um contexto de produção ambíguo, podendo dificultar a tarefa do aluno. No que se refere à dimensão do léxico específico da escrita - tipologias e géneros - o enunciado instrucional não apresenta vocabulário específico, nomeadamente não identifica a tipologia ou o género de texto a produzir, não orientando, desta forma, o aluno na sua tarefa, como faz o exemplo 2 ("Escreve uma carta..."). É importante ter sempre em conta o conteúdo da tarefa, procurando usar uma terminologia que não seja redundante, inadequada, pouco relevante ou incoerente com a atividade a realizar, especialmente no que se refere a léxico da área da linguística textual, da análise do discurso e da pragmática. O exemplo 1, retirado de um teste diagnóstico de português, pela forma como está estruturado, poderá levar os alunos a tomar variadas opções como cenário de resposta relativamente ao tipo de texto a produzir, porque, na verdade, não é dada a indicação de uma tipologia textual que possa orientar o aluno na produção: num texto de opinião, um género argumentativo, apenas é enunciada a intencionalidade - dar opinião. A configuração textual que essa opinião pode assumir ficará ao critério do escritor/aluno, uma vez que "Escreve um texto..." pode assumir a forma de diferentes géneros, desde que argumentativos.

\subsection{2 - Nível morfossintático}

O nível morfossintático está relacionado com a organização dos elementos que constituem o enunciado instrucional. A falta de clareza, o uso de uma ordem incorreta e a escassez de precisão na sua construção, claramente, afetam as construções gramaticais utilizadas. O enunciado instrucional deve ser produzido tendo a capacidade de transmitir a mensagem da forma mais objetiva possível. Este nível caracteriza-se, igualmente, pela forma como distribui os referentes lexicais e anafóricos, as repetições, as substituições lexicais e pronominais, para permitir a progressão e a gestão do conteúdo temático e uma melhor compreensão do mesmo. Os enunciados instrucionais devem estar produzidos sem ambiguidades e sem redundâncias para que o 
aluno não encontre possíveis dificuldades ou obstáculos na interpretação/ descodificação desses enunciados. Por exemplo, o enunciado instrucional 1 apresenta a repetição do verbo "escrever". O aparecimento pela segunda vez do verbo "escrever" poderia ser substituído ou mesmo evitado, porque esse comando já está dado e assumido pelo aluno a partir do momento em que iniciou a leitura do item instrucional. A expressão "teus argumentos" apresenta-se como redundante, uma vez que, ao formular e apresentar a sua opinião, o aluno estará a construir argumentos. Ainda no exemplo 1, o uso da modalidade deôntica expressa em "como deve comemorar" pode causar ambiguidade na compreensão do enunciado instrucional, na medida em que o locutor poderá sentir que está a agir perante o seu interlocutor "amigo", impondo/obrigando-o a cumprir uma situação expressa no texto escrito: escrevendo uma carta com uma moldura de texto prescritivo, perdendo-se a intencionalidade comunicacional da carta. Para além disso, é necessário que o aluno tenha um conhecimento formado sobre como comemorar uma qualquer festa/época especial do ano para que não se iniba relativamente ao ato de escrita pelo leque de possibilidades que oferece a expressão "época especial". Poder-se-á contar com o pacto comunicacional existente entre o professor e o aluno para completar a informação, caso esta atividade seja uma proposta de sala de aula; no entanto, este exemplo foi retirado de um teste de avaliação.

\subsection{3 - Nível textual}

Não se pode esquecer que o enunciado instrucional possui as mesmas propriedades que um texto de maior extensão (Amor 1999). A sua produção implica, assim, uma dimensão textual e um conjunto de implicações. O nível textual do enunciado instrucional pressupõe coerência semântica e coesão. Estes são fatores que muitas vezes são negligenciados na formulação e, consequentemente, interferem na compreensão dos enunciados instrucionais e, por sua vez, nos resultados. Na formulação dos enunciados instrucionais, torna-se importante a coerência, na medida em que é necessário não incluir elementos semânticos que sejam contraditos em relação ao conteúdo temático introduzido, para não desviar a atenção do aluno do objetivo principal da tarefa; como refere Amor, há um "grau de previsibilidade mínimo que um texto deve satisfazer, em termos de funcionamento da língua e de lógica do mundo/do saber, sem o qual o texto se arriscaria a perder coerência." (1999: 33). A expressão "aconselhares relativamente à forma como deve comemorar uma época festiva", do exemplo 2, que solicita a escrita de uma carta, exige uma relação entre o conhecimento que o aluno possui e o conhecimento do mundo solicitado, que, caso não exista, pode interferir na relação entre estes e a previsibilidade que se espera que o aluno consiga na escrita/produção do seu 
texto. Neste âmbito, o estudo das unidades linguísticas transcende os limites da oração. Várias são as formas de levar os alunos a aproximarem-se do produto texto, numa perspetiva de processamento da informação de planificação, com as sequências prototípicas e sua compreensão e ordenação. Falamos de níveis de macroestrutura e superestrutura do esquema organizativo dos textos, que, fazendo parte do enunciado, constituem um auxílio nos processos de produção textual, dimensão não conseguida no exemplo 3 . Este exemplo 3 revela-se um enunciado instrucional ambíguo pela quantidade de comandos e de informação que solicita ao aluno gerir numa mesma tarefa: "descrever", "estabelecer relação" e "justificação". Pode aqui encontrar-se uma tentativa de orientar o aluno na sua tarefa recorrendo às sequências textuais de Adam (1992), e aqui estaremos no nível da textualidade, no entanto, esta estruturação pode levar o aluno a compor o seu texto como se se tratasse de partes autónomas e não uma unidade com relações entre os diferentes períodos e parágrafos. $\mathrm{Ou}$ seja, a nível de tessitura textual, pode perder-se a coesão e até a coerência. Recorde-se que, quanto mais vaga e confusa se apresenta a instrução, mais dificuldade o aluno terá em realizar mentalmente um modelo do produto que deverá ser capaz de elaborar, faltando, assim, pragmaticamente, informação que lhe permita entender a intencionalidade da/desta tarefa de escrita.

\subsection{4 - Nível discursivo-pragmático}

Concomitante com o nível discursivo, encontra-se o nível pragmático que o enunciado instrucional deve possuir para desempenhar a sua função reguladora/avaliativa. O género como objeto comunicativo, constituído por enunciados, possui um significado literal ou proposicional, uma dimensão intencional que tem consequências na audiência: a relevância do que se transmite, a forma como o outro pode cooperar no ato comunicativo, o princípio de cortesia subjacente ao modo como se transmite a mensagem. Isto é, o objetivo do enunciado instrucional varia em relação ao objetivo proposto por quem o formula.

A observação dos enunciados instrucionais destinados à produção escrita revela que as informações dadas por estas instruções não se devem limitar ao caráter gramatical, possuindo também uma dimensão discursiva. No que se refere ao nível discursivo, é necessário compreender que o enunciado se apresenta de forma linear, no entanto, "conlleva a que sea necesaria una configuración externa que arme los contenidos, su ordenación y su organización" (Calsamiglia \& Tusón 2008: 85). O enunciado, enquanto objeto comunicativo, vai criar um contexto ao aluno que lhe permitirá configurar e relacionar os elementos necessários à realização da tarefa. Esta contextualização do produto a escrever deve ser indicada, por exemplo, pela 
identificação do género alvo de aprendizagem ou de avaliação, como no exemplo 2, géneros esses que correspondem a cada esfera de conhecimento e de atividade humana (Bronckart 2003) e que devem ser do conhecimento do aluno, para que aconteça a cooperação na comunicação, correspondendo às expetativas do aluno. A indicação do género permite ao discente contextualizar a sua atividade e enquadrá-la numa situação espaciotemporal definida. Esta condição permite-lhe tomar decisões relativamente às escolhas linguísticas que terá de fazer para, assim, mostrar o seu desempenho. As condições necessárias do momento de produção dizem respeito ao contexto em que é produzido, ainda que esse contexto seja o escolar (Schneuwly \& Dolz 2004). De acordo com Maingueneau, a este aspeto estão associados alguns constituintes que se "articulam de maneira estável por meio de instituições de linguagem definidas em termos de contratos verbais ou de géneros de discurso" (Maingueneau 1997: 27), e são eles: os participantes do discurso, o seu enquadramento espaciotemporal e os seus objetivos/ finalidades. No que respeita ao contexto físico, temos o lugar de produção (espaço físico em que o texto é produzido), o momento de produção (tempo em que o texto é produzido), o enunciador (aquele que produz o texto) e o coenunciador (aquele a quem se destina o texto, no entanto, fisicamente presente apenas na oralidade, ausente fisicamente no momento da escrita). O exemplo 2, retirado de um teste de avaliação de 9.. ano, apresenta explicitamente os aspetos discursivos que estão intrinsecamente indicados pelo género a ser produzido, que é identificado. $\mathrm{O}$ género epistolar exige a definição dos papéis de locutor e interlocutor para que a sua função se possa cumprir. Desta forma, está criado, assim, o contexto da situação de comunicação exigido e que vai possibilitar ao aluno enquadrar o seu registo de língua, escrito, num registo familiar "dirigida a um amigo". No entanto, no que se refere à intencionalidade, à finalidade de escrita da carta, ao contrário do enunciado instrucional do exemplo 1, o objetivo proposto é ambíguo, uma vez que não é contextualizado temporalmente. A expressão "comemorar uma época especial do ano" é vaga, podendo referir-se a uma festividade qualquer, estando dependente do momento em que foi aplicado o teste. A análise deste enunciado coloca questões como: não seria possível concretizar essa/uma época especial? Se este enunciado instrucional 2 pertencesse a um manual, compreender-se-ia que a atividade pudesse ser realizada em qualquer momento do ano letivo e, portanto, o professor poderia fornecer as indicações em falta, ajustando à(s) época(s). O facto de aparecer num teste altera completamente esta possibilidade. Perante a descodificação deste enunciado instrucional, a liberdade que é dada ao aluno para tomar decisões pode constituir um obstáculo no momento da produção textual e, consequentemente, no momento da avaliação. $\mathrm{O}$ enunciado não oferece 
orientações precisas ao aluno. Perante enunciados instrucionais como este, como se podem prever critérios de classificação/avaliação da competência de escrita mediante a diversidade de possibilidades que o enunciado instrucional permite? A pouca orientação do enunciado instrucional abre a possibilidade de o aluno se questionar sobre: por que razão teria de o aconselhar? O seu amigo não partilha a mesma cultura? Que amigo é este? Neste exemplo, o enunciado instrucional poderia possuir mais informações relativas à dimensão discursiva e, desta forma, levar o aluno a compreender a razão da escrita da sua carta.

No exemplo 1, não é possível especificar os aspetos-chave para conduzir o aluno no processo de escrita: desconhece(m)-se o(s) destinatário(s), quem vai ler este texto, bem como a situação discursiva que enquadra este ato comunicativo, que ajudaria o aluno a tomar decisões a nível lexical, morfossintático e de estrutura textual. Dependendo de quem é o destinatário ou o contexto - situação de comunicação, intencionalidade - que enquadra o texto, assim se fazem escolhas relativas a um registo mais formal ou menos formal, uma maior ou menor necessidade de utilizar a/determinada modalidade discursiva, uma vez que se fala de expressar opiniões. Os aspetos referentes à situação de comunicação devem ser tidos em conta na formulação dos enunciados para que não constituam um aspeto problemático quer a partir da sua formulação, por parte de quem os constrói (professor), quer a nível da compreensão, por parte dos alunos, e possibilitar ao professor ter uma verdadeira ideia das competências dos alunos no momento de diagnose/avaliação. Ainda que o enunciado do exemplo 1 preveja a escrita de um texto argumentativo através da expressão "escreve os teus argumentos", essa informação não é dada de forma explícita, com clareza. Esta formulação possui orientações vagas, o que pode ter como resultado a possibilidade de cada aluno fazer uma interpretação diferente, dando origem a produtos/objetos textuais diferentes. Os resultados a obter podem não estar previstos nos critérios de classificação/correção do professor. Lembre-se que, no exame final de $9 .^{\circ}$ ano, nos critérios de correção/classificação, no que se refere à resposta extensa, um dos parâmetros a avaliar é o parâmetro A, designado "Tema e Tipologia", onde se prevê que o aluno seja capaz de reconhecer a tipologia textual e as respetivas características.

No exemplo 3, também os aspetos discursivos não foram bem conseguidos, uma vez que, para além da falta de intencionalidade do texto, também as coordenadas comunicativas que permitem (re)criar o/um contexto de produção estão omissas, não se encontrando referidos nem o(s) recetor(es), nem o lugar de circulação do texto. A representação da situação comunicativa deveria contribuir para (re)criar a cena enunciativa e, assim, ajudar o aluno a definir o seu papel enquanto enunciador do discurso a produzir. A necessidade das 
coordenadas para a configuração da situação comunicativa está relacionada com o facto de esta contribuir para a construção de um determinado modelo mental de conduta discursiva que influencia quer o comportamento dos intervenientes, quer o resultado, ou seja, como referem Pasquier e Dolz, "Não se trata, pois, de «compor» um texto a partir de elementos simples conhecidos, mas de «produzir» um texto como resposta a uma situação de comunicação complexa, recorrendo a múltiplos instrumentos e estratégias." (1996: 36).

Todos estes níveis linguísticos concorrem na construção do enunciado instrucional e entram em jogo no momento em que os alunos enfrentam a tarefa de compreender o enunciado e, consequentemente, de o empreender através do cumprimento da atividade solicitada por esse mesmo enunciado.

\section{5 - Algumas considerações}

Estas observações assumem uma maior relevância quando se tem de verificar/avaliar os diferentes aspetos da produção que serão premiados com um resultado. $\mathrm{O}$ enunciado instrucional deve incluir explicitamente todos os aspetos necessários à situação de comunicação se não se quiser incorrer em situações de injustiça no momento da avaliação. Alguns enunciados instrucionais dificilmente ajudam o aluno a organizar os seus escritos de forma coesa e coerente e, assim, mostrar o seu conhecimento no que se refere ao domínio da escrita e do conhecimento linguístico que a mesma exige. Significa, então, que, na avaliação desses exercícios, seja no decurso da sala de aula ou em momentos específicos de avaliação, o professor terá de ser bastante flexível nas diferentes possibilidades que certamente vão ser apresentadas como resultado final.

Tendo em conta que os enunciados instrucionais fazem parte do discurso instrucional, é importante destacar que a sua produção tem o objetivo de levar o interlocutor, o aluno, através da interação, a executar uma ação determinada em atividades de sala de aula e em contexto regulador e avaliativo. Este é um discurso que pretende regular a atividade do interlocutor, do processo à ação, que é prática e mental. Isto indica que o item deve estar formulado/ deve formular-se com precisão e clareza para que a tarefa solicitada seja executada de forma coesa e coerente.

Num primeiro momento, o aluno assume-se como leitor desse enunciado instrucional e, a partir das informações que encontra, tem uma participação ativa na construção do sentido por meio da mobilização do contexto a partir de pistas e sinalizações que o enunciado instrucional the oferece. Essa participação é tanto mais ativa e efetiva consoante as informações que estejam ao seu dispor. Da primeira fase, concomitantemente, nasce uma segunda fase do processo: papel de produtor, onde revela o nível de 
compreensão. A partir da compreensão do enunciado instrucional, o aluno tem de conseguir projetar o objeto textual requerido e concretizá-lo através da escrita. O aluno produtor desenvolve assim um "projeto" de (como) dizer.

Cumpre referir que, nos estudos de apreensão do sentido dos enunciados, não se pode colocar de lado a questão dos diversos níveis de significação que cada texto possui. Por outras palavras, além da significação explícita, existe toda uma gama de significações implícitas, muito mais subtis, diretamente ligadas à intencionalidade do emissor (Koch 2002: 160). Isso implica dizer que as interações verbais instrucionais não ocorrem fora de um contexto socio-histórico - a aula - e, sendo assim, a compreensão de enunciados exige do interlocutor não apenas uma compreensão semântica, mas uma análise do contexto do item/enunciado de instrução. É verdade que os enunciados instrucionais fazem parte do pacto comunicacional entre professores e alunos em situação de ensino e aprendizagem e que, portanto, o conhecimento do professor pode colmatar; no entanto, nem sempre estes enunciados são mediados pelo professor, sendo disso exemplo os enunciados 1 e 2 retirados de provas.

As últimas palavras são destinadas ao professor que usa o enunciado instrucional para também refletir sobre a sua prática, voltando a referir que se pretende que o conhecimento do professor se afirme por um "saber profissional mais analítico, consistente e em permanente atualização, claro na sua especificidade, e sólido nos seus fundamentos." (Roldão 2007: 102). Uma vez que, como referido inicialmente, o enunciado instrucional também permite (re)definir e (re)orientar a sua prática, tomando como exemplos estes enunciados, que tipo de reflexão poderá um professor fazer sobre a (sua) prática?

\section{REFERÊNCIAS}

Adam, J.-M. 1992. Les Textes: types et prototypes. Paris: Nathan.

Amor, E. 1996. Didática do Português - fundamentos e metodologia. Lisboa: Texto Editora.

Amor, E. 1999. A dimensão linguística dos instrumentos de avaliação. In P. F. Pinto (org.). Português. Propostas para o futuro. 3. Avaliação. Lisboa: APP, 27-40.

Atorresi, A. 2005. Construcción y evaluación de consignas para evaluar la escritura como competencia para la vida. Enunciación. (10): 4-14.

Bakthin, M. 2003. Estética da criação verbal. São Paulo: Martins Fontes.

\footnotetext{
${ }^{6}$ Agradeço aos revisores anónimos os pertinentes comentários que me permitiram apurar a versão final deste texto.
} 
Bloom, B. S.; Engelhart, M. D.; Furst, E. J.; Hill, W. H.; Krathwohl, D. R. 1956/1996. Taxonomy of educational objectives. New York: David Mckay.

Bronckart, J. P. 2003. Atividade de linguagem, textos e discursos: por um interacionismo sócio-discursivo. São Paulo: Educ.

Calsamiglia, H.; Tusón, A. 2003. Las cosas del decir. Barcelona: Ariel.

Castro, R. V. 1998. A leitura e a escrita em contexto escolar. In: R. V. de Castro; M. de L. Dionísio (orgs.). Entre linhas paralelas. Estudos sobre o português nas Escolas. Braga: Angelus Novus, 39-54.

Castro, R. V. 1995. Para a análise do discurso pedagógico. Constituição e transmissão da gramática escolar. Braga: Universidade do Minho/Instituto de Educação e Psicologia/Centro de Estudos em Educação e Psicologia.

Charaudeau, P.; Maingueneau, D. 2008. Dicionário de Análise do Discurso. São Paulo: Editora Contexto.

Dolz, J.; Gagnon, R.; Decâncio, F. 2011. Produção Escrita e Dificuldades de Aprendizagem. Campinas: Mercado das Letras.

Duarte, I. M; Rodrigues, S. V.; Machado, A.; Guedes, M. M.; Toriz, H. 2016. A escrita escolar para expressão de conhecimentos e aprendizagens: um caso em estudo. In: J. A. B. Carvalho; M. de L. Dionísio; E. de C. Mesquita; J. Cunha; A. Arqueiro (orgs.). Atas do V Simpósio Internacional de Ensino de Lingua Portuguesa e do V Fórum Ibero-Americano de Literacias ( $V$ SIELP-FIAL). Braga: CIEd/Universidade do Minho, 219-232). Disponível em http://repositorium.sdum.uminho.pt/handle/1822/44992.

González, I. A. 2005. Instruções de Escrita. Direções de trabalho e critérios de construção textual. Lisboa: DGIDC. ME.

Grossman, P. 1990. The making of a teacher: teacher knowledge and teacher education. New York: Teachers College Press.

Kerbrat-Orecchioni, C. 1990. Les Interations Verbales I-Approche interactionnelle et structure des conversations. Paris: Armand Colin.

Koch, I. 2002. Desvendando os segredos do texto. São Paulo: Cortez.

Maingueneau, D. 1997. Os Termos-Chave da Análise do Discurso. Lisboa: Gradiva. 1. ${ }^{a}$ edição.

Marcuschi, L. A. 2001. Marcas de interatividade no processo de textualização na escrita. Texto policopiado (inédito), 1-14.

Marcuschi, L. A. 2008. Produção Textual, Análise de Gêneros e Compreensão. São Paulo: Parábola Editorial.

Neves, A.; Ferreira, A. 2015. Avaliar é preciso? Guia Prático de avaliação para professores e formadores. Lisboa: Guerra e Paz.

Pasquier, A.; Dolz, J. 1996. Um decálogo para ensinar a escrever. Cultura y Educácion. 2: 31-41.

Riestra, D. 2002. Lectura y escritura en la universidad: las consignas de las tareas en la planificación de la reenseñanza de la lengua. RIILL - Revista del 
Instituto de Investigaciones Lingüisticas y Literarias Hispanoamericanas. 15: 54-68.

Riestra, D. 2010. Lectura y escritura en la universidad: las consignas de tareas en la planificación de la reenseñanza de la lengua. In: Enunciación. 1(15): 173-181.

Roldão, M. C. 2005. Formação de Professores, construção do saber profissional e cultura da profissionalização: que triangulação? In: L. Alonso; M. C. Roldão (Orgs.). Ser professor de $1 .^{\circ}$ ciclo - Construindo a profissão. Braga: CESC/Almedina, 13-26.

Roldão, M. C. 2007. Função docente: natureza e construção do conhecimento profissional. Revista Brasileira de Educação. 34(12): 94-103.

Schneuwly, B.; Dolz, J. 2004. Gêneros Orais e Escritos na Escola. Campinas: Mercado das Letras.

Shulman, L. S. 1987. Knowledge and teaching: foundations of a new reform. Harvard Educational Review. 1(57):1-22.

Shulman, L. S. 2004. Research on teaching: a historical and personal perspective. In: L.S. Shulman. The wisdom of practice: essays on teaching, learning, and learning to teach. San Francisco: Jossey-Bass, 364-381.

Tormenta, J. R. 2003. Manuais escolares de língua portuguesa. Como conciliá-los com a Reorganização Curricular? In: C. Mello (org.). Didáctica das línguas e das literaturas em Portugal. Contextos de Emergência, Condições de existência e modos de desenvolvimento. Coimbra: Pé de Página, 257-261.

Van Dijk, T. 2016. Discurso y conocimiento. Barcelona: Gedisa Editorial.

Van Dijk, T. 2010. Cognição, discurso e interação. São Paulo: Editora Contexto.

Vygotsky, L. S. 1998. Pensamento e Linguagem. São Paulo: Martins Fontes. 2. ${ }^{a}$ edição. 